\title{
Functional and Nutritional Characteristics of Cassava Flour (Lafun) Fortified with Soybeans
}

\author{
Bankole ${ }^{1}$, Y.O. \\ Tanimola ${ }^{1}$, A.O. \\ Odunukan ${ }^{1}$, R.O. \\ Samuel ${ }^{2}$, D.O. \\ ${ }^{1}$ Department of Agricultural \& Bio-Environmental Engineering, \\ Lagos State Polytechnic, Ikorodu-Nigeria \\ ${ }^{2}$ Department of Food Technology; School of Technology, \\ Lagos State Polytechnic, Ikorodu-Nigeria
}

\section{Doi:10.5901/jesr.2013.v3n8p163}

\begin{abstract}
This study was designed for nutrition fortification of cassava flour lafun with soya beans. Five different samples of lafun to soya beans were (100:0, 90:10, 80:20, 70:30, and 60:40). The following proximate analysis of these samples were carried out ash determination, crude fiber, protein, moisture and fat. The results ranges were $0.84-2.46 \%, 1.63-2.12 \%, 1.16-12.54 \%, 13.01$ $11.28 \%$ and $0.44-2.62 \%$ respectively. Functional properties of the formulation were also evaluated and the result obtained showed that loose and packed bulk density were $0.2-0.3 \%$ and 0.5 $0.55 \%$, the water absorption and oil capacity were $163-127 \%$ and $167-113.5 \%$ respectively. Swelling capacity and disposability were also 6.2-2.95\% and 93.7-81.4\% while the regulation and solubility are 24.5-18.99 and 6.7-4.95 respectively. The pasting properties results were also revealed that at a peak of 244.17-112.33rvu, the trough was 129.17-58.83rvc, and the breakdown was 115.00-52.50rvu, the final viscosity was between 164.33-81.92rvu, set back 35.17-23.08rvu, peak time $4.46-3.91$ and pasting temperature $63.15-63.85^{\circ} \mathrm{C}$.
\end{abstract}

Keywords: Functional-characteristics, nutritional-characteristics, cassava flour, fortified, soya-beans.

\section{Introduction}

Food security remain an unfulfilled dream for more than 800 million people (Anuonye, 2011) who are unable to leave healthy and active lives because they lack assess to safe and nutritious food. More than 840 million people lack access to enough food to meet their daily basic needs, while more than one third of the world's children are stunted due to diets inadequate in quantity and quality (WHO, 2001). Cassava Manihot esculanta spp. is one of the perennial crops grown throughout the lowland tropics. It is a major staple food crop in Nigeria supplying about $70 \%$ of the daily calorie to over 50 million Nigerians. World consumption of cassava for food is concentrated in the developing countries. For instance, in Africa about $70 \%$ of cassava production is used as food and most popular processed products are garri, lafun, fufu, kpokpo gari and a dry granular meal made from moist and fermented cassava is most commonly used in West Africa (Sanni, et a/ 2009). Processing of cassava to flour is one of the food means of utilizing this important food crop. Processing of cassava roots also serve as an important means of preserving food crop.

Aside processing the cassava to lafun, its root can be cooked and eaten while the fermented and ground tubers could be baked into different processes. Lafun is one of the local names given to 
flour made from cassava in Nigeria. It is produced through the submerged soaking of cassava roots in water for about 2-3 days in order for fermentation process to take place, the product will be sun dry before milling of dried fermented roots to flour. The fermented cassava flour could then be mixed with boiled water to form dough and consumed with soup. It is carbohydrate food that can be eaten with soup. The protein source is the fish or meat in the soup. During fermentation of cassava to lafun various microorganisms were involved and these include Bacillus substilis, Klebsiela spp., Candida tropicals (Oyewole, 1990). The major limitation in lafun like other cassava product includes low protein content, low minerals, and vitamins and present of cyanide toxicity. Cassava is protein(1-2\%) deficient, though it contains low amount of methionine, lysine, and tyrosine ( Akubor and Ukwuru ,2003). Cassava cause toxicity through hydrolytic breakdown and release hydrocyanic acid. However glycosides present are reduced to safe levels by traditional method of processing. Efforts have been made to address the protein deficiencies of cassava product including lafun. One possible solution has been the incorporation of soya beans to cassava products.

The incorporation of soybeans, groundnut and other seed protein into cassava meal has been shown to yield fortified products of high protein values. Jishaa, Sheriff and Padmajaa (2010) revealed that low protein and poor functionality limit the use of cassava flour in snack foods, which were modified using blends with cereal and/or legume flours. Some food products have been incorporated with soybeans; like traditional fermented maize foods with soybeans weaning foods with soybeans for baby, development of non-wheat soybean fortified biscuit, performance of extruded maize, cassava, sorghum wheat, soybean flour for bread production, etc. Daniel and Osho (2005) revealed that fortification of lafun will increase the nutritive value of consumer that takes in the food. This also reduces the kwashiorkor which is a major disease of people that lack protein. This purpose of this study was to investigate the nutritive attributes of lafun fortified with soybean. Specifically, it will investigate the following:

1. The functional attributes of lafun fortified with soybean

2. The nutritional attributes of lafun fortified with soybean.

3. Consumer acceptability of lafun fortified with soybean.

\section{Methods and Procedure}

Matured cassava root (Odongbo) used in this research was obtained from Alabata farm settlement in Abeokuta Ogun state. Soybeans were purchased from Ikorodu market in Lagos state. The soybeans were processed into soybeans full fat. Mature cassava root were sorted, peeled and washed after peeling. It was latter cut into smaller sizes and soaked for twenty-two days. This was sieved to remove the fibers and was sun dried for two days. It was then milled into flour and sieved with $0.25 \mathrm{~mm}$ mesh to remove the coarse fiber particle present. Unfermented cassava Lafun fortified with soybeans was analyzed for moisture content, protein, ash, crude fiber, carbohydrate and amylase in the ratio of 100:0 for the control, 90:10, 80:20, 70:30 and 60:40 (Cassava :Soybean).

\subsection{Proximate Analysis of Soybean-lafun}

\subsubsection{Determination of the Moisture Content}

About five grams of each sample were accurately weighed into a pre-weighed aluminum dry dish. The samples were dried to constant weight in an oven at $105^{\circ} \mathrm{C}$ for $3 \mathrm{hrs}$ (AOAC, 1990).

$\%$ moisture content was obtained as shown below.

$\%$ moisture content $=\frac{M 2-M 0}{M 1-M 0} \times 100$

Mo $=$ weight of the aluminum dish

M1 =weight of fresh sample of dish 
M2 = weight of dry sample of dish.

\subsubsection{Determination of Crude Protein}

$1 \mathrm{~g}$ of each sample was introduced into the digestion flask. Kjehadi catalyst ( 5 selenium table) was added to the sample. 20millitre of concentrated acid was added and allowed to stay for 8hrs until a clear solution was obtained. The cooled digestion was transferred into $100 \mathrm{ml}$ volumetric flask and made up to mark with distilled water. The distillation apparatus was rinsed and set up. $20 \mathrm{ml}$ of $4 \%$ borkc acid was pipetted into conical flasks and 5 drops of methyl- red added to each flask as indicator. Samples were later diluted with $75 \mathrm{~m} /$ distilled water; $10 \mathrm{ml}$ of the digest was made alkaline with $20 \mathrm{ml}$ of sodium hydroxide $(20 \%)$ and distilled. The steam exhaust of the distillation apparatus was closed and the change of color of boric acid solution to green was fixed. The mixture was distilled for 15 mins (AOAS) and the filtrated were titrated against $0.1 \mathrm{~m}, \mathrm{HCL}$.

The percentage total Nitrogen was calculated as shown below

$\%$ Total Nitrogen $=\frac{\text { Titre value } \times \text { normality }}{\text { Weight of sample }} \times 0.014 \times 100$

$\%$ crude protein $=\%$ total Nitrogen $\mathrm{x}$ conversion factor $=6.25$

\subsubsection{Determination of Crude Fibre}

The fat in the sample was removed $5 \mathrm{~g}$ of fat free sample was weighed into $600 \mathrm{ml}$ beaker and $100 \mathrm{ml}$ of trichloroacetic acid (TAC) was added. The sample was boiled and refluxed for 4mins, cooled and thereafter filtered with what man No4 filter paper. The residue was washed with hot distilled water and methylated spirit. The filter paper together with the sample was transferred into a crucible in an oven overnight at $1000 \mathrm{c}$ for $6 \mathrm{hrs}$, and weighed again after cooling weight during incineration. The loss in equivalent to amount of crude fibre.

$\%$ crude fibre $=\frac{(W+A)-(W+B)}{\text { sample weighed }} \times 100$

Weight $A=$ weight after drying

Weight $B=$ weight of sample after Aching

\subsubsection{Determination of Crude Fat}

5 grams of the sample was weighed and put in thimbles and plugged with cotton wool. The thimble was dried and inserted into a sox let system HT (a) the extraction cup was inserted into the sox let extractor and extracted for 15 mins in the boiling and $30-45$ mins in the rinsing position.

The $\%$ fat in the sample was calculated as follows

$\%$ Fat $=\frac{W 1-W 2}{W 1} \times 100$

W1 $=$ weight of the sample

W2 = weight of the empty cup

W3 = weight of the cup with the extracted oil.

\subsubsection{Determination of the Ash Content}

5 grams of the sample was weighed into porcelain crucibles previously ignited and weighed. Organic matter was charred by igniting the material on a hot plate in the fume cupboard. The crucibles were placed in the muffle furnace and maintained at $6000 \mathrm{C}$ for $6 \mathrm{hrs}$. They were later cooled in desiccators and weighed, immediately. The percentage Ash content was shown below.

$\%$ Ash $=\frac{(\text { Weight of crucible }+ \text { Ash })-(\text { Weight of empty crucible })}{\text { Sample weight }} \times 100$ 


\subsection{Functional Properties Determination}

\subsubsection{Solubility Index Determination}

Solubility was done by weighing $1 \mathrm{~g}$ of sample in $20 \mathrm{ml}$ distilled water in test tube. This was subjected to heating in a water bath at a temperature of $60^{\circ} \mathrm{Cfor} 30 \mathrm{mins}$ because there was no appreciable heating, it was subjected to configuration at $1200-\mathrm{pm}$ for $20 \mathrm{mins}$ and $10 \mathrm{ml}$ of the supernatant was decanted and dried to constant weight. The solubility was expressed as the percentage by weight of the dissolved starch from a heated solution.

\subsubsection{Swelling Capacity Determination}

$0.1 \mathrm{~g}$ of sample was weighed into a test tube containing $10 \mathrm{ml}$ distilled water and then heated in a water bath at temperature of $600 \mathrm{c}$ for 30 mins. This was continually shaken within the heating period. The test tube was centrifuged at high speed for $15 \mathrm{mins}$ after heating in order to facilitate the removal of supernatant water which was then carefully decanted and the weight of starch paste taken.

$$
\text { Swelling capacity }=\frac{\text { weight of starch paste }}{\text { Weight of dry starch sample }}
$$

\subsubsection{Emulsion Capacity}

$1 \mathrm{~g}$ of sample was made into slurry in $20 \mathrm{ml}$ of distilled water in an Greenberger flask by stirring at 100 rpm for 15 mins and edible oil was added and stirring continued another. The system was then transferred into a centrifugal tube to separate into two layers.

$$
\text { Emulsion Capacity } \%=\frac{\text { Height of emulsified layer }}{\text { Height of whole layer }} \times 100
$$

\subsubsection{Oil Absorption Capacity}

$2 \mathrm{~g}$ of the sample was added to $20 \mathrm{ml}$ of oil and a graduated centrifugal tuber. The mixture was stirred to dispense the samples in oil. Sample was then allowed to stand for 30 mins, at $300 \mathrm{C}$ after which it was centrifuged at 350rpm for 30 mins as water absorption capacity. The excess oil absorbed was expressed as the percentage oil bound by sample after the mixture has been pinioned into a measuring cylinder.

$$
10 \%=\frac{\text { Volume of bound water }}{\text { Weight of sample }}
$$

\subsubsection{Bunk Density Determination}

$10 \mathrm{~g}$ of the sample were weighed into a weighed $25 \mathrm{ml}$ of graduated cylinder. The cylinder was gently tapped ten times against the palm of the hand; the bulk density was expressed as the weight of the sample per volume occupied by the sample $(\mathrm{g} / \mathrm{ml})$.

\subsubsection{Foaming Capacity Determination}

$2 \mathrm{~g}$ of the sample was whipped with $50 \mathrm{ml}$ of water for 30 mins in a blender at a speed "soft" and "mine" and was poured into a $100 \mathrm{ml}$ graduated measuring cylinder to know the volume.

Foaming capacity $=\frac{\text { Volume after whipping-Volume before whipping }}{\text { Volume before whipping }} \times 100$ 


\subsubsection{Foaming Stability Determination}

$0.5 \mathrm{~g}$ of the sample was blended $30 \mathrm{mins}$ in distilled water at top speed in a moulinex blender. The whipped mixture was transferred into a graduated cylinder. The blender was rinsed with $10 \mathrm{ml}$ of distilled water which was then greatly added to the graduated cylinder. The foam volume in the cylinder was recorded per sample after 30mins standing.

\subsubsection{Water Absorption Capacity}

About $2 \mathrm{~g}$ of the sample was mixed with $20 \mathrm{ml}$ of distilled water in a graduated centrifugal tube. The mixtures were stirred to dispense the sample in distilled water. Samples were then allowed to stand for 30mins at $300 \mathrm{C}$ after which it was centrifuged at very high speed (between 3500 rpm to $1000 \mathrm{rpm}$ ) for $30 \mathrm{mins}$. The volume was noted in a graduated cylinder after having been poured into it. Density of water was taken to be $1 \mathrm{~g} / \mathrm{ml}$ excess water absorbed was expressed as the percentage water bound by $100 \mathrm{~g}$ of sample and the absorption capacity calculated thus,

$$
10 \%=\frac{\text { Volume of bound water }}{\text { Weight of sample }} \times 100
$$

\subsubsection{Dispensability}

$10 \mathrm{~g}$ of sample was placed in $10 \mathrm{ml}$ measuring cylinder and distilled water was added to reach the graduated volume $100 \mathrm{ml}$. The mixture was stirred vigorously and allowed to settle for $3 \mathrm{hrs}$. The volume of the settled particles was recorded and deducted from 100 and the difference reported as percentage dispensability

\subsubsection{Determination of Amylase}

$0.1 \mathrm{~g}$ of flour sample was weighed into $100 \mathrm{ml}$ volumetric flask and $1 \mathrm{ml}$ of $95 \%$ Ethanol was added to wet the sample. $10 \mathrm{ml}$ of $0.5 \mathrm{MKOH}$ was added and the mixture was held overnight at room temperature. The mixture was diluted to $100 \mathrm{ml}$ with distilled water and again held overnight at a room temperature. $5 \mathrm{ml}$ aliquot of the diluted solutions was pipette out of the mixture into another $100 \mathrm{~m} /$ volumetric flask and three drops of $0.1 \%$ phenolphthalein solutions were added. The resulting solution was neutralized using IMACHLIMHCL droproise until neutral $\mathrm{pH}$ was achieved. $2 \mathrm{ml}$ of 0.2 lodine solutions was added to the neutralized solutions and made to volume with distilled water. Standard solutions of amylase of range $0-10 \mathrm{ppm}$ were prepared from 100ppm stock amylase solution and treated similarly like sample above. The absorbance or optical density of samples as well as standard solutions of different concentrations range were taken after $30 \mathrm{mins}$ of addition of $0.2 \%$ iodine solution on a spectronic $12 \mathrm{D}$ spectrophotometer at a wavelength of $630 \mathrm{~nm}$.

$\%$ Amylase was calculated using:

Absorbance of sample $\times$ Gradient factor $\times$ dilution factor 10000

\subsection{HCN-Determination of HCN Content}

About $10 \mathrm{~g}$ of each sample were diluted with $20 \mathrm{ml}$ distilled water and Ogawasaki cyanide ion selective electrode was used after the instrument have been calibrated with oil and 10ppm standard solution of potassium cynide.

\subsubsection{Pasting Properties of HCN Content}

Pasting properties were determined according to the Newport (1998) procedure. The pasting properties of the sample based on $100 \%$ dry matter were determined by mixing the sample with 
$25 \mathrm{ml}$ distilled water and placed into canister. The paddle was placed into the canister which in turn was inserted into the instrument. The measurement cycle was initiated by depressing the motor tower of the instrument. The RVA machine was loaded and was set at $40^{\circ} \mathrm{C}$ and allowed to run for 20 mins. The canister was removed on the completion of the test.

\subsubsection{Sensory Evaluation}

Sensory Evaluation for soy-lafun from each of the proportion was performed by 30 panelists. 5 samples of soy-lafun flour were presented to the panelists who determine the sample based on the following attributes; taste, color, texture, drawness, and overall acceptability of the sample using the following hedonic scale.

Like extremely (9); Like very much (8); Like moderately (7); Like slightly (6);

Neither like nor dislike (5); Dislike slightly (4); Dislike moderately (3);

Dislike very much (2) and Dislike extremely (1)

The samples were labeled as follows: SSF-01 (100\% cassava); SSF-02 (90:10\%);

SSF-03 ( 80:20\%); SSF-04 (70:30\%); SSF-05 (60:40\%)

\section{Results}

\subsection{Proximate Composition of Soy-lafun}

Table 1: Proximate Compositions of soybeans sample

\begin{tabular}{|l|c|c|c|c|c|}
\hline Parameters & SSF01 & SSF02 & SSF03 & SSF04 & SSF05 \\
\hline Moisture & 13.01 & 12.04 & 11.6 & 11.52 & 11.28 \\
\hline Ash & 0.84 & 1.71 & 2.08 & 2.39 & 2.46 \\
\hline Protein & 1.16 & 4.63 & 7.87 & 11.7 & 12.54 \\
\hline Crude Fibre & 1.63 & 1.81 & 1.94 & 2.07 & 2.12 \\
\hline Fat & 0.44 & 1.85 & 2.47 & 2.55 & 2.62 \\
\hline
\end{tabular}

The raw flour without fortification has $1.2 \%$ protein, $1.6 \%$ of crude fibre, $0.4 \%$ fat, $0.8 \%$ ash and $13.01 \%$ of moisture content which is almost the same as the chemical composition of cassava as reported by several studies. Table 1 also shows the chemical composition of soybeans full fat at various levels of fortification. The crude fat, protein, Ash, crude fibre and moisture content decrease in levels of supplementations. Although, there is an overall higher value with soybean full fat fortification. Generally, from the observation it could be deduce that there was an appreciable increased in the chemical composition of soy-lafun fortification with increase in addition with soybeans on lafun.

Table 2: Functional Properties of Soybeans Samples

\begin{tabular}{|c|l|c|c|c|c|c|}
\hline Parameters & & SSF01 & SSF02 & SSF03 & SSF04 & SSF05 \\
\hline \multirow{2}{*}{ Loosed (Bulk) } & \multirow{2}{*}{ Mean standard deviation } & 0.2897 & 0.2896 & 0.3622 & 0.2818 & 0.32765 \\
& & 0.000283 & 0.0003 & 0.0001 & 0.0002 & 0.32765 \\
\hline \multirow{2}{*}{ Packed (Density) } & \multirow{2}{*}{ Mean standard deviation } & 0.5283 & 0.58836 & 0.5716 & 0.51305 & 0.55535 \\
& & 0.01 & 0.00015 & 0.0001 & 0.00025 & 0.00025 \\
\hline \multirow{2}{*}{ WAC } & \multirow{2}{*}{ Mean standard deviation } & 1.63 & 156.5 & 149.5 & 140 & 1.27 \\
& & 1.414214 & 2.5 & 1.5 & 3 & 1 \\
\hline \multirow{2}{*}{ OAC } & \multirow{2}{*}{ Mean standard deviation } & 167 & 129.5 & 1.29 & 121.5 & 113.5 \\
& & 2.8284827 & 1.5 & 0 & 1.5 & 1.5 \\
\hline SC & Mean standard deviation & 8.2 & 7.85 & 7.4 & 7.7 & 6.65 \\
\hline
\end{tabular}




\begin{tabular}{|c|l|c|c|c|c|c|}
\hline & & 0.141421 & 0.05 & 0.1 & 0.1 & 0.15 \\
\hline \multirow{2}{*}{ EC } & \multirow{2}{*}{ Mean standard deviation } & 7.2 & 11.3 & 13.4 & 14.6 & 16.05 \\
& & 0.1 & 0.1 & 0.1 & 0.1 & 0.15 \\
\hline \multirow{2}{*}{ FC } & \multirow{2}{*}{ Mean standard deviation } & 6.205 & 5.4 & 4.35 & 3.65 & 2.95 \\
& & 0.095 & 0.1 & 0.15 & 0.15 & 0.15 \\
\hline \multirow{2}{*}{ Dispersibility } & \multirow{2}{*}{ Mean standard deviation } & 93.7 & 88,6 & 86.65 & 84 & 81.4 \\
& & 0.1 & 0.1 & 0.15 & 0.6 & 0.1 \\
\hline \multirow{2}{*}{ Gelation Ca } & \multirow{2}{*}{ Mean standard deviation } & 24.595 & 23.515 & 21.71 & 20.405 & 18.99 \\
& & 0.015 & 0.025 & 0.04 & 0.025 & 0.13 \\
\hline \multirow{2}{*}{ Solubility } & \multirow{2}{*}{ Mean standard deviation } & 6.7 & 6.4 & 6 & 5.555 & 4.95 \\
& & 0.2 & 0.1 & 0.1 & 0.15 & $0.25 \mathrm{~S}$ \\
\end{tabular}

The water absorption capacity on raw flour without fortification is $163 \mathrm{~g} / 100 \mathrm{~g}$. The foaming capacity range of SSF 01 is $6.2 \%$ while SSF 05 with highest fortification has $2.95 \%$. Solubility index is an indication of how soluble the sample is and its ability to gelatinize with much residual particles. Gelatin indicates that the energy requirements and cost of providing energy for gel formation will be relatively high which is economically advisable. The sample with highest fortification has the lowest value which is $18.99 \%$ while sample with no fortification has the highest value which is $24.5 \%$.

Table 3: Pasting properties

\begin{tabular}{|l|c|c|c|c|c|}
\hline Parameters & SSF 01 & SSF 02 & SSF 03 & SSF04 & SSF05 \\
\hline Peak 1 & 244.17 & 183.83 & 148.83 & 119.25 & 112.33 \\
\hline Trough 1 & 129.17 & 85.50 & 73.08 & 76.17 & 58.83 \\
\hline Breakdown & 115.00 & 98.33 & 75.75 & 43.08 & 52.50 \\
\hline Final viscosity & 164.33 & 119.42 & 101.92 & 98.7581 .92 & \\
\hline Set back & 35.17 & 33.92 & 28.83 & 22.58 & 23.58 \\
\hline Peak time & 4.46 & 4.14 & 4.01 & 4.53 & 3.91 \\
\hline Pasting temp. & 63.15 & 63.15 & 64.35 & 63.70 & 63.85 \\
\hline
\end{tabular}

The results obtain for the pasting properties is as shown in Table 3. The result showed that, there was increase in the sample SSF01 for the peak viscosity due to the no fortification which was in the range of 244.17 while there is a decrease in the other sample as the introduction of soybeans being introduced. A singular observation was made for tough, breakdown, viscosity, setback, peak time and pasting temperature. The pasting temperatures of the entire sample were in the range of $63-63.85^{\circ} \mathrm{C}$. Peak time for the samples was also in the range of 4-4.6. Breakdown was in the range of 115.00-52.50. Trough was 129-58.8, set back also decrease from 35.17-23.08. Final viscosity ranges from 164-81.92. It also observed that most of the starchy products also showed the progressive rise in the viscosity with increase in the concentration.

\section{Conclusion}

From the result of this study, lafun can be fortified and well accepted at $10 \%$ of levels of fortification with soybeans flour. The least preferred sample was 60:40 levels of fortification. Therefore, soybeans flour is relatively high in protein contents with the levels of Lysine, Tryptophan and certain minerals which provide a sound basis for using soy flour to supplement Cassava flour. 


\section{References}

Akubor, P.I. and Ukwuru, M.U. (2003). Functional properties of biscuit making potential of soybean and cassava flour blends. Plant Foods for Human Nutrition. Vol. 58: 1-12. Kluver Academic Publishers.

Anuonye, J.C. (2011). Soybean utilization and fortification of indigenous foods in times of climate changes. Available online: www.interchopen.com ISBN 978-958-307-534-1

Daniel, O. and Osho, P. (2005). Nigeria Food J ournal Vol. 23., pp40.

Eke O.S. and Akobundu E.H.T. (1998): Functional Properties of African Yambean seed flour as affected by processing. Journal of Food Chemistry 48:337-340.

J ishaa, S., Sheriffa, J.T. and Padmajaa, G. (2010). Nutritional, functional and physical properties of extrudates from blends of cassava flour with cereal and legume flours: International Journal of Food Properties. Vol. 13, (5) DOI: 10.1080/10942910902934090

Sanni, L.O., Onadipe, O.O., Ilona, P., Mussagy, M.D., Abass, A. and Dixon, A.G.O. (2009). Success and challenge of cassava enterprises in West Africa: A case study of Nigeria, Benin and Sierra Leone. International Institute of Agriculture (IITA). www. iita.org 